\title{
An analysis on Aerodynamics Performance Simulation of NACA 23018 Airfoil Wings on Cant Angles
}

\author{
Setyo Hariyadi S.Pa \\ aLaboratory of Mechanics and Fluid Machine, Department of Mechanical Engineering \\ Industrial Technology Faculty \\ Institute Teknologi Sepuluh Nopember (ITS) \\ e-mail: hudzaifahsetyo@gmail.com
}

\begin{abstract}
Winglet attached on the tip of aircraft wings to increase lift. Mainly, winglet used for increasing aerodynamic efficiency, it decreases induced drag caused by vortex on wings tip. The phenomenon of vortex is collision of highpressured air below the wings meet the low-pressured air above it that cause turbulence. Induced drag may reach $40 \%$ of total drag during cruising, and 80 $90 \%$ while take off. A procedure to decrease induced drag is using wing tip devices. It used on commercial aircrafts and the most frequently used is blended winglet. Numerical study conducted to examine the best aerodynamic performance of sub-sonic plane wings in angles of attack. Analysis on NACA 23018 airfoil wings with blended winglet on the tip was conducted. Freestream velocity of $40 \mathrm{~m} / \mathrm{s}$ or $R e=1 \times 10^{6}$, and angle of attack (a) $0^{\circ}, 5^{\circ}, 10^{\circ}$, and $15^{\circ}$ are used. Evaluation for parameter includes coefficient pressure (Cp), velocity profile, lift, drag, and ratio $C_{L} / C_{D}$. Obtained contour are pressure contour, velocity, and vorticity. In view of all this, there is increasing performance of aerodynamic with $C_{L} / C_{D}$ ratio of wings with blended winglet and plain wing. Reaching current angle of attack, the function of winglet is gradually decrease.
\end{abstract}

Keywords: winglet; angle of attack; induced drag; blended winglet; $C_{L} / C_{D}$ ratio

\section{INTRODUCTION}

In 1970s, biologists observed the characteristics of flying birds such as eagle, hawk, and osprey. Each of it has great lift on its sticking out feathery long wings with parallel aperture formation in specific distance (multilpewinglets) on the tip. The biologists found that the part of the wing purposed to decrease drag when the bird flies.

Aircraft wings with additional winglet had been researched for dozens of years ago. Whitchomb (1976) from research center of NASA Langley had firstly patented the use of winglet for commercial aircraft in 1970s. He attached blade on kc-135A wing tip and tested it to fly in 1979 and 1980 . That research shown that additional winglet can increase lift for $7 \%$ during flight. Its lift-drag efficiency increases 10 to $15 \%$.

In Europe, wing grid had been developed as additional part attached on airfoil tip. It is a unit of additional small wings attached on wing tip. These small wings are set in various angles to cleave powerful vortex on the tip that smaller vortex lost its energy, which leads to lift distribution change and induced drag on wings decrease. This concept implemented on glidder aircraft with exciting result. But, unfortunately, it was ceased as it cannot change the characteristics of flight to convince drag decrement. Finally, research had been desisted with indefinite form and optimum performance.

CFD is very useful in variance of future applications. It is, of course, the application of fluid flow on place/device or others. CFD is mostly used in industry - simulation frequently used is conducted by using FLUENT software. For instance, the use of CFD in 
industry is to simulate flow on vehicle or for more specific the use of CFD to observe the interaction of propeller or rotor with aircraft fuselage. Rotor and propeller can be represented by modelling with complex variation.

CFD abbreviated from Computational Fluid Dynamics is computation technique to predict, to simulate, and to analyze fluid flow, heat transfer, and chemistry reaction. CFD used computational numerical analysis method using basic fluid flow equation such as Navier-Stokes equation, and equation/principle of constancy as conservation of mass and energy.

As a developing discipline, CFD has special notice from international communities in line with computerized-digital development. Primary development included two important things. First, how to make physical fluid phenomenon model that is very difficult with experiment such as system/weather condition of space supersonic vehicle. The second is the ability to analyze system that the expense is effective without using directly testing procedure.

Basic concept of using CFD software is solution for numeric method with a fluid equation, it is Navier-Stokes Equation, by principle of:

1. Conservation of mass

2. Conservation of momentum

3. Conservation of energy

The idea raised to develop computation technique with CFD is a meaningful progress in advanced technology. An analysis by means of simulation before prototype built can minimize cost as it avoid product failure. Besides, product development by company is also possibly simulated by the CFD software before it is directly manufactured. By means of CFD, it also simplifies communication between mechanic and electric division in designing product for company, and directly save the cost.

Dinesh, et al. (2014) used air foiltip NACA 0012 and blended winglet with variation of cant angle. On his work, cant angle of $60^{\circ}$ gives highest $C_{L}$, yet it has relatively higher $C_{D}$. Cant angle of $15^{\circ}$ give better $C_{\llcorner} / C_{D}$ distribution. It could happen because of drag profile as the influence of viscosity and surface stiffness. Besides, pressure drag occurs on the front part of airfoil is not stabilized by the rear part.

Myilsamy, et al. (2015) used swept back wing airfoil NACA 4412 with blended winglet on normal wing, $30^{\circ}$ winglet and $90^{\circ}$ winglet. Research on this simulation used K$\omega$, steady state, and velocity inside of $50 \mathrm{~m} / \mathrm{s}$. It results better performance on winglet cant angle of $30^{\circ}$ toward angle of attack $(A \circ A) 2^{\circ}$, it leads to change on total current and drag coefficient variation. Moreover, this research shown the increment on winglet design with variation of proper cant angle can minimize induced drag caused by vortex on wing tip.

NACA 23018 airfoil wings of Cessna 421 Golden Eagle with endwall attached on the wall was used and the tip is added with blended winglet cant angle of $90^{\circ}$ in length variation of winglet chord line. It is aimed to observe in detail the influence of adding blended winglet toward the increment of wing performance and the decrement of drag on any angle of attack. The use of CFD may present such contours; pressure and vorticity magnitude. Besides, comparison of L/D would be presented as enhancement parameter of aircraft performance.

\section{Methodology}

Numerical simulation used to conduct this research was by means of simulation software with turbulence model of K- $\omega$ SST. Freestream current velocity used was $40 \mathrm{~m} / \mathrm{s}$ $\left(\operatorname{Re}=5 \times 10^{6}\right)$ with angle of attack $(\alpha)=0^{\circ}, 5^{\circ}, 10^{\circ}$, and $15^{\circ}$. Specimen model is NACA 23018 airfoil with and without winglet. The winglet is blended winglet with $90^{\circ}$ cant angle. Reynolds Number determined based on chord. In this case, cord length is $10 \mathrm{~cm}$. Figure 2.1 is simulation domain and border condition used in simulation. 


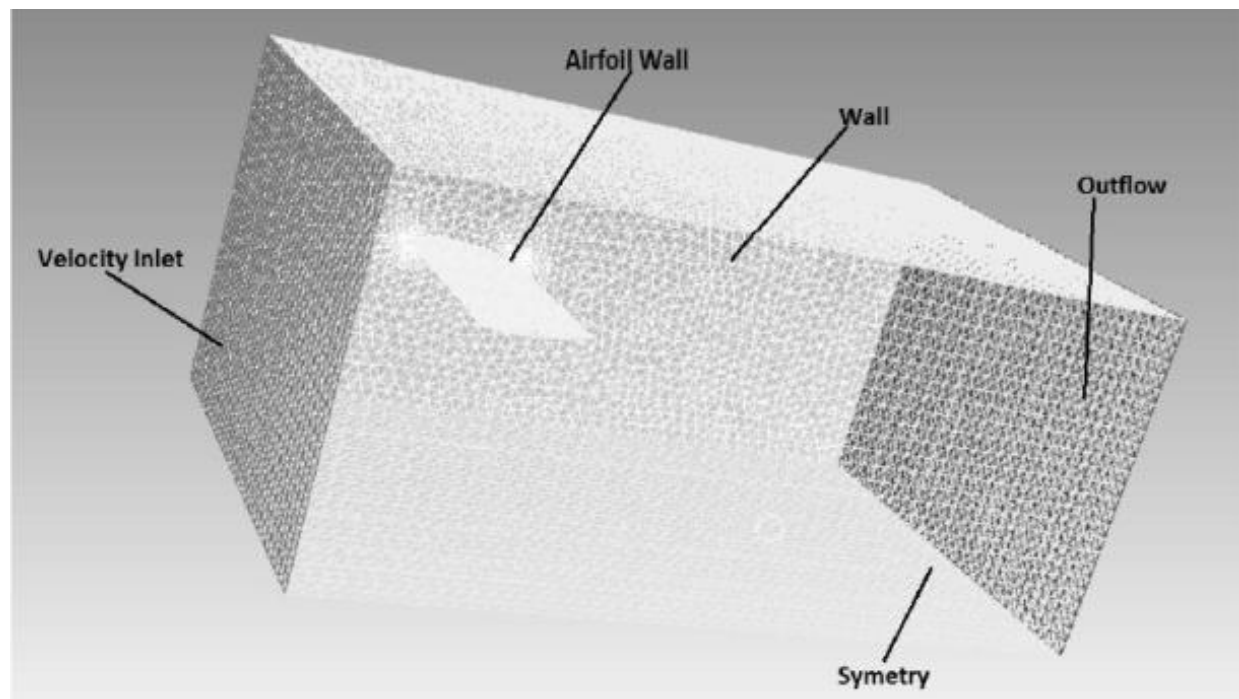

Figure 2.1 Meshing and 3D airfoil modeling domain

The next modeling dimension depicted on figure 2.2.

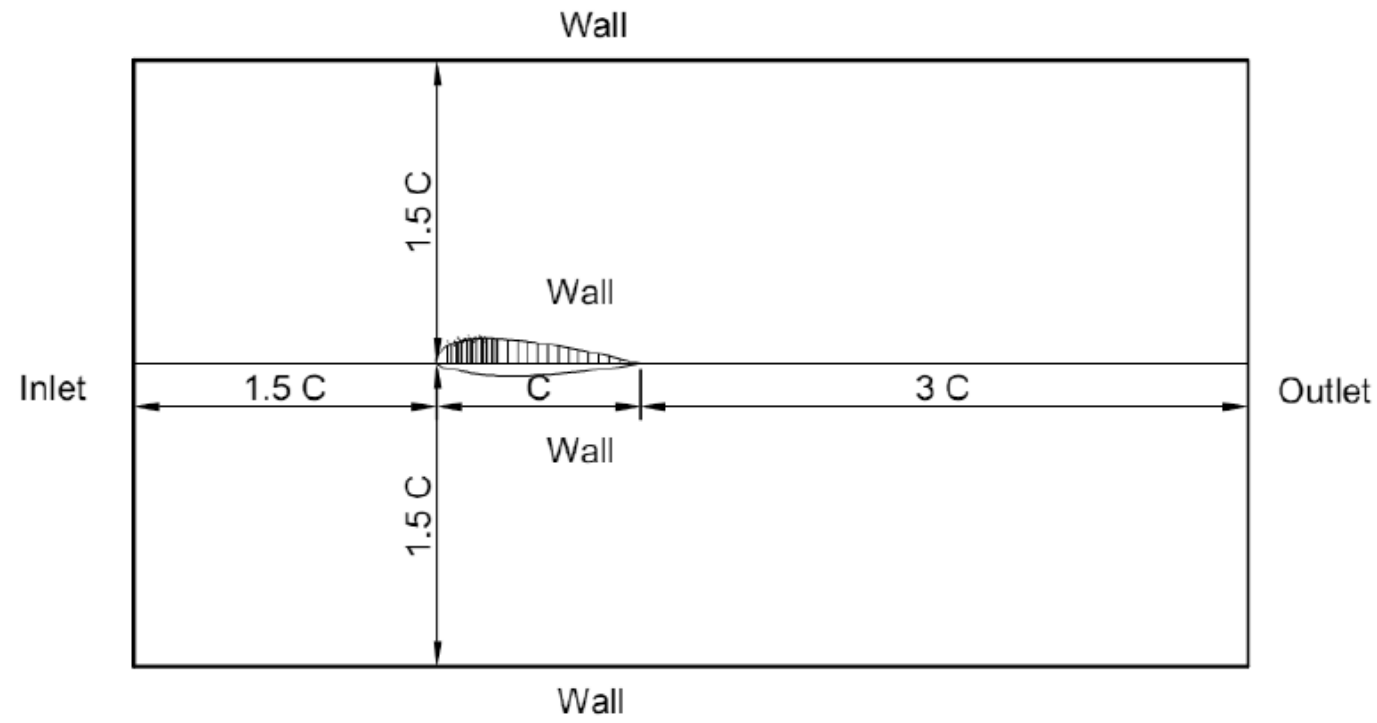

Figure 2.2 Modeling dimension (Mulvany, 2004)

Specification of wing and winglet presented on Table 2.1 and Table 2.2.

Table 2.1 Specification of wing

\begin{tabular}{cll}
\hline No. & \multicolumn{1}{c}{ Description } & \multicolumn{1}{c}{ Dimension } \\
\hline 1 & Airfoil Type & NACA 20318 \\
2 & Wing Type & Straight Constant Chord \\
3 & Sweep Angle & $14^{\circ}$ \\
4 & Wing Span & $20 \mathrm{~cm}$ \\
5 & Aspect Ratio & 0,5 \\
6 & Maximum Chord & $3,48 \mathrm{~cm}$ \\
\hline
\end{tabular}




\begin{tabular}{cll}
\multicolumn{1}{c}{ Table 2.2 Specification of winglet } \\
\hline No. & \multicolumn{1}{c}{ Description } & \multicolumn{1}{c}{ Dimension } \\
\hline 1 & Winglet Type & Blended Winglet \\
2 & Winglet Span & $0,8 \mathrm{C}$ \\
3 & Winglet Chord Line & $0,4 \mathrm{C} ; 0,5 \mathrm{C} ; 0,6 \mathrm{C} ; 0,7 \mathrm{C}$ \\
4 & Wing tip Thickness & $0,04 \mathrm{C}$ \\
\hline
\end{tabular}

Specimen model is NACA 23018 airfoil with and without winglet on the tip in the form of blended winglet as depicted on Figure 2.3.

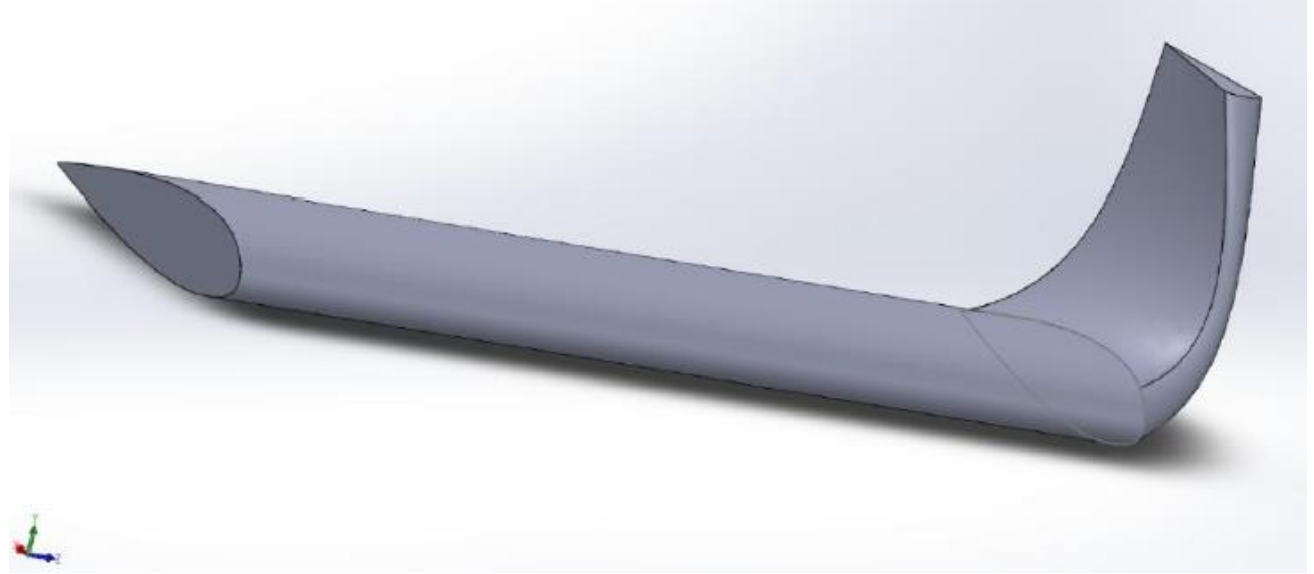

Figure 2.3 NACA 23018 wing airfoil specimen with blended winglet cant angle of $90^{\circ}$

Sort and properties of material included is appropriate to environment condition, on $30^{\circ} \mathrm{C}$ temperature and $1 \mathrm{~atm}$ pressure. This modeling used air as work fluid, $(\rho)=1,17$ $\mathrm{kg} / \mathrm{m}^{3}$, viscosity $(\mu)=1,86 \times 10^{-5} \mathrm{~N} . \mathrm{s} / \mathrm{m}^{2}$. Turbulence intensity on this numerical modeling is $0,8 \%$ and length scale of inlet is $0,024 \mathrm{~m}$. Turbulence modeling used is viscous turbulent k- $\omega$ SST. Solution used second order for pressure, momentum turbulent kinetic energy, and turbulent dissipation rate. Convergence criteria determined for $10^{-5}$, it means iteration process regarded as convergent after its residue reached smaller value than $10^{-5}$.

Using simulation software requires data accuracy both post-processing and preprocessing. Grid independence is needed to determine the rate also the best and the most efficient grid structure that modeling result close to the actual.

Grid independence was conducted to obtain the number of constant meshing. On this process, the number of meshing is divided into 4 sorts and is observed the smallest difference of each meshing by comparing $C_{D}$ numeric graphic. $C_{D}$ value from grid independence presented on table 3.

Table 2.3 An analysis on Grid Independence of Aifoil 23018 Dimension without winglet,

\begin{tabular}{ccccc}
\multicolumn{5}{c}{$R e=5 \times 10^{6}$} \\
\hline Meshing & Base Size & Number of Cell & Number of Face & Cd \\
\hline A & 148.140 & 714.403 & 1.680 .754 & 0.0301 \\
B & 315.510 & 1.738 .460 & 3.894 .706 & 0.0210 \\
C & 311.959 & 1.718 .133 & 3.861 .727 & 0.0255 \\
D & 406.304 & 2.179 .934 & 5.089 .013 & 0.0211 \\
\hline
\end{tabular}

Table 2.3 presents grid independence of plain airfoil. Based on table 2.3, inclined smaller $C_{D}$ value available on Meshing $B$ and Meshing $D$. One consideration in executing numeric simulation is time and memory used, for next simulation Meshing $B$ is used. 


\section{Result ANd Discussion}

The air flown above and below the wing is actually not passed the wing, but otherwise the wing "go through" the air. Yet, we assume the flow by visualizing motionless wing. By curved form, the flowing air above the wing needs longer distance and makes them "flush" faster than air flow below the wing. As air velocity is faster above the wing, the pressure is lower than the air "flush" below the wing. Bigger pressure below the wing will "elevate" aircraft wing and it is called as lift.

Therefore, aircraft speed kept in design. As the speed goes down, the lift would be decrease and the aircraft fall down. In aviation, it is called as stall. Minimum speed called as stall speed. If aircraft speed more than its design, the high speed stall could take place. Flight in straight and level (straight and flat) can be maintained by low speed to the high speed. A pilot should adjust angle of attack and thrust in all speed regimes if the aircraft had to stand in current level (level flight). There are varies of speed during level flight and without acceleration, $C_{L}$ proportion (Coefficient of Lift) and $C_{D}$ (Coefficient of Drag) can be calculated on any angle of attack. Plotting result for lift/drag (L/D) ratio on current angle of attack shows that $\mathrm{L} / \mathrm{D}$ increase to maximum and reduced on lift coefficient and bigger angle of attack as depicted on figure. Note that maximum L/D ratio take place on specific angle of attack and coefficient. If the aircraft flight on stable with $\mathrm{L} / \mathrm{D}$ max, the total of drag is minimum. Smaller or bigger angle of attack on $\mathrm{L} / \mathrm{D}$ max will reduce $L / D$ ratio and the consequence is increasing total of drag from lift for aircraft. Therefore, the main concern of engineers is mostly on resistance and lift than distribution of pressure and shear stress. Results of experiment usually obtained and presented directly in resistance and lift. There are two important principles should be followed in designing object with low resistance:

- If the object is long and thin, the resistance related to friction. The resistance can be reduced by keeping as much laminar flow as possible. It represents subtle surface.

- If the object is blunt, the resistance especially form resistance has high Reynolds number. This resistance can be decreased by delaying separation as long as possible. One of the ways is by bringing forward the transition to border layer of turbulence. The better method is streamlining, it lengthen the rear part of object. Aerodynamic consideration is important in designing vehicle as the aircraft. The aircraft has force that avoid its rate, it is aerodynamic resistance. Aircraft machine should continuously supplied force to overcome the resistance load.

\subsection{Downwash and Wing tip Vortex Reduction vs. Winglet Performance}

Wing is real 3D form of airfoil. Process of forming lift on the wing equals to airfoil. In despite of wing comprised of airfoil distributed along wing span, the limited range effect leads to the flow pattern around the wings ignored as $2 \mathrm{D}$ flow.

Lift on a wing surface take place if there is pressure difference between above and below surface. This difference will occur along the span, except on wing tip. Pressure equalization process occurred on this wing tip that air flow encounters rotation around wing tip. Therefore, effectively, the flow around the wing is 3D flow. Rotation on this wing tip is called as wing tip vortex, which in the line of aircraft forward movement, wing tip vortex will move backward the wing and forth below. This vortex influences wing that means giving impact below speed component of flow around the wing. Downward induction velocity is called as downwash. Downwash and $\mathrm{V}_{\infty}$ show lower local angle of attack than geometric angle of attack.

As observed that the most needed winglet function is saving fuel for aircraft. Performance research shows that winglet design should be optimized to obtain maximum advantage on cruising and non-cruising conditions. Comprehensive numerical study had 
been conducted in this study to examine the best performance of subsonic wing aircraft on angle of attack variation that is validated with $3 \mathrm{D} \mathrm{k- \omega}$ model.

On Figure 3.1, there is comparison on lift coefficient $\left(C_{L}\right)$ and drag coefficient $\left(C_{D}\right)$ of angle of attack with and without winglet oriented to different chord line winglets. Generally, it proves that by attaching winglet can reduced induced drag and increase lift. However, it also shows that between chord lines winglet length has optimum value despites of only has slightly effect on decreasing drag and increasing lift. Increasing angle of attack raised drag and lift, but increment of wing with winglet unable to show linear increment as plain wing.

Wing performance with attached winglet is also reported significantly increase as depicted on Figure 3.2. L/D ratio increases more effectively than plain wing. It also reaches maximum on $10^{\circ}$ angle of attack and after that it tends to be on the level flight as a matter of fact decreases like depicted on Figure 3.3 and 3.4. The highest increment of $\mathrm{L} / \mathrm{D}$ ratio shown on chord lines winglet $\mathrm{x} / \mathrm{c}$ 0,4 than other chord lines. From the above proof, it can be concluded that the smaller chord lines winglet, the higher L/D ratio.

Table 3.1 Drag Coefficient

\begin{tabular}{cccccc}
\hline Degree & Plain & $\mathbf{x} / \mathbf{C ~ 0 . 4}$ & $\mathbf{x} / \mathbf{c ~ 0 . 5}$ & $\mathbf{x} / \mathbf{c ~ 0 . 6}$ & $\mathbf{x} / \mathbf{c ~ 0 . 7}$ \\
\hline 0 & 0.0211 & 0.0256 & 0.0255 & 0.0268 & 0.0249 \\
5 & 0.0366 & 0.0297 & 0.0301 & 0.0295 & 0.0304 \\
10 & 0.0502 & 0.0389 & 0.0399 & 0.0394 & 0.0401 \\
15 & 0.0639 & 0.0538 & 0.0539 & 0.0547 & 0.0545 \\
\hline
\end{tabular}

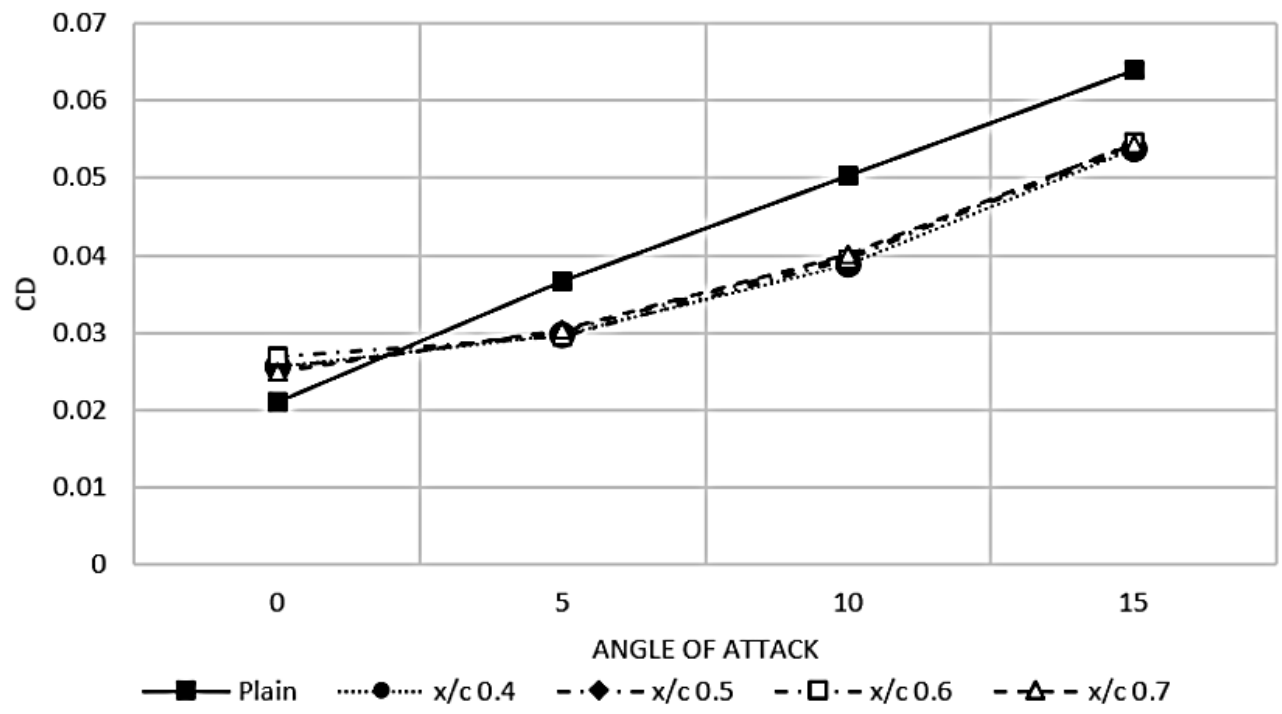

Figure 3.1 Lift Coefficient

Table 3.2 Lift Coefficient

\begin{tabular}{cccccc}
\hline Degree & Plain & $\mathbf{x} / \mathbf{c ~ 0 . 4}$ & $\mathbf{x} / \mathbf{c ~ 0 . 5}$ & $\mathbf{x} / \mathbf{c ~ 0 . 6}$ & $\mathbf{x} / \mathbf{c ~ 0 . 7}$ \\
\hline 0 & 0.0164 & 0.0207 & 0.0213 & 0.0233 & 0.0244 \\
5 & 0.0802 & 0.0992 & 0.1020 & 0.1002 & 0.1032 \\
10 & 0.1407 & 0.1792 & 0.1796 & 0.1762 & 0.1791 \\
15 & 0.1936 & 0.2365 & 0.2422 & 0.2434 & 0.2403 \\
\hline
\end{tabular}




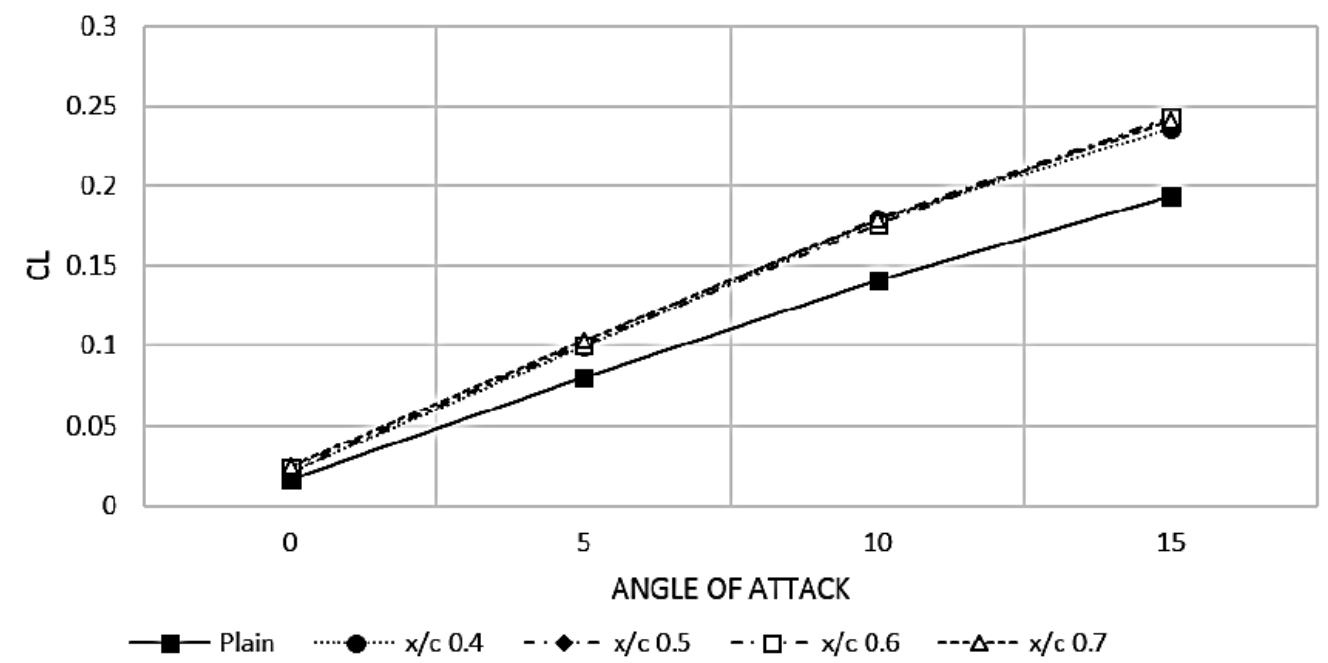

Figure 3.2 Lift Coefficient
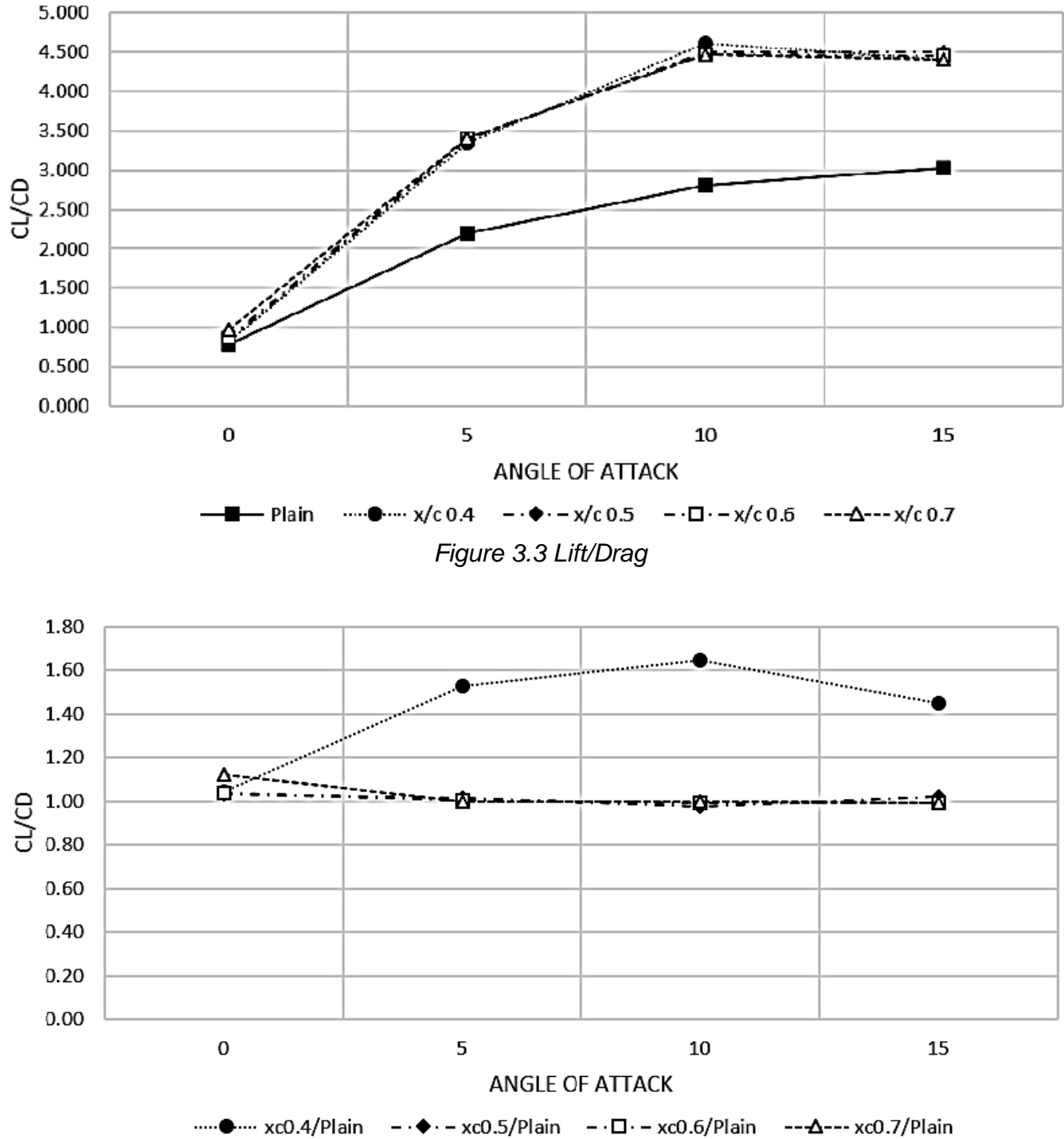

Figure 3.4 Lift/Drag compared with plain wing 


\subsection{Flow Visualization}

Figure 3.5 presents pressure contour on plain winglet and wing attached with winglet by chord lines length $x / c 0.4$. Plain wing shows that on $0^{\circ}$ to $10^{\circ}$ has increment pressure on lower surface and decrement on upper surface. On the tip, it shows the influence of air jump from lower surface with higher pressure and upper surface with lower pressure. Fluid jump from lower surface leads to reduced effective area of the wing. It is shown on pressure contour of the tip on uneven lower and upper surfaces. Specifically on upper surface, contour on the tip is higher than on other upper surface area.
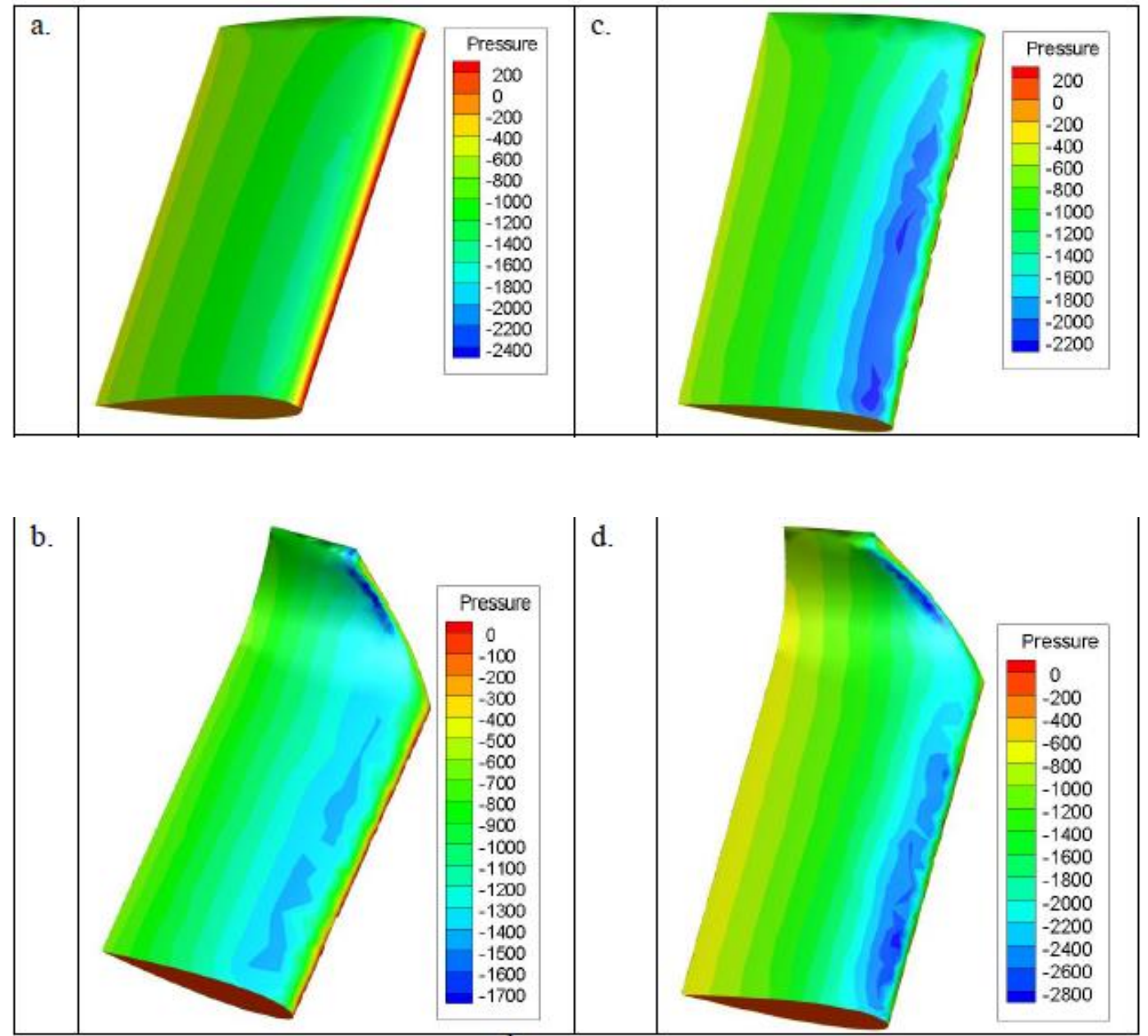

Figure 3.5 Pressure distribution on $\mathrm{Re}=5 \times 10^{6}$ plain wing with $90^{\circ}$ cant angle chord lines winglet $x / c$ 0.4. a. Plain $0^{\circ}$, b. $0^{\circ}$ AoA $90^{\circ}$ cant angle $x / c$ 0.4, c. Plain $10^{\circ}$, d. $10^{\circ}$ AoA $90^{\circ}$ cant angle $x / c 0.4$.

Furthermore, Figure 3.6 shows vortices intensity on the rear of wing with twofold chord wing length. On low angle of attack, turbulence intensity on plain wing seems to be higher than wing with winglet. Yet, increasing angle of attack forms vorticity in the rear of wing. The higher angle of attack, the vorticity is stronger and significant. Blended wing decreases the vorticity. 

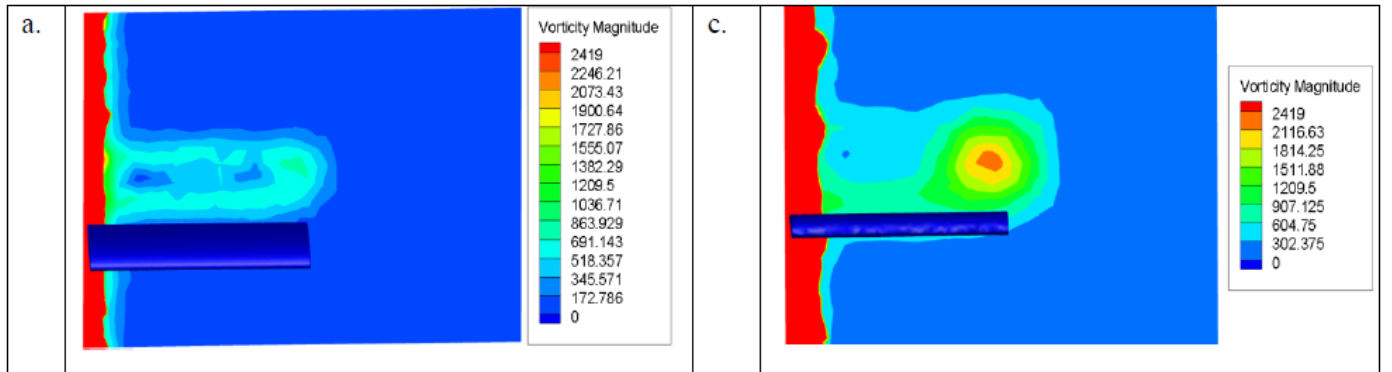

b.
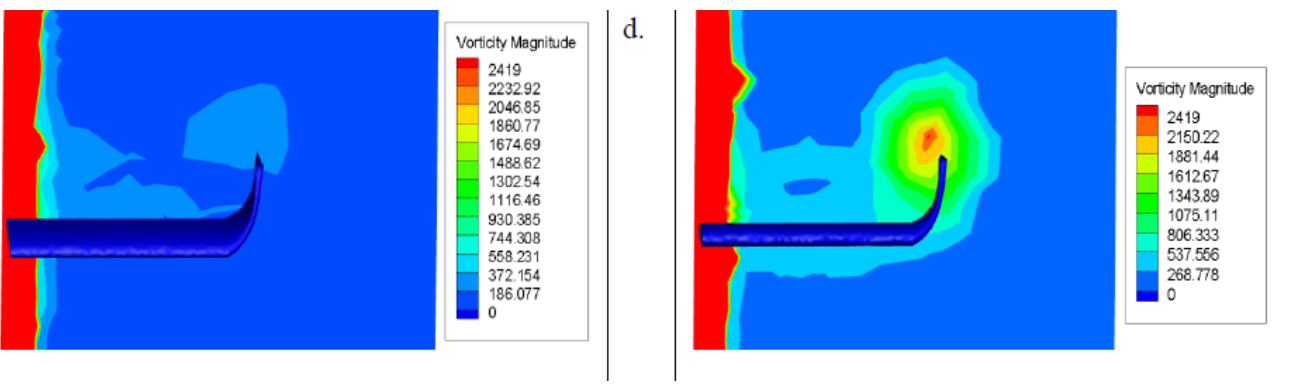

Figure 3.6 Distribution of vorticity magnitude on $\mathrm{Re}=5 \times 10^{6}$ plain wing with $90^{\circ}$ cant angle and $\mathrm{x} / \mathrm{c}$ 0.4 chord lines winglet. a. Plain $0^{\circ}$, b. $0^{\circ}$ AoA $90^{\circ}$ cant angle $x / c 0.4$, c. Plain $10^{\circ}$, d. $10^{\circ}$ AoA $90^{\circ}$ cant angle $\mathrm{x} / \mathrm{c} 0.4$.

Using blended winglet, vortex strength can be reduced and effective area of lower and upper surface can be increased. Pressure contour shown by wing with blended winglet proves that upper surface has higher pressure between lower and upper surface. It is based on ratio calculation of L/D on wing with higher winglet than plain wing. Induced drag is also reduced. The increment of $C_{L} / C_{D}$ takes place in between because of wing effective area is better. Tip vortex from lower side wing contribute to reduce this effective area and increase induced drag from wing. If winglet effectively functions it is able to restrain the tip vortex.

\section{Conclusion}

This research used Computational Fluid Dynamic (CFD). Result of this research represents increment on wing performance after attached with blended winglet even it increases drag because of increasing angle of attack. Yet, lift is better with winglet attachment than plain wing. Winglet causes tip vortex forming reduced significantly. From numerical review, it is obtained that the use of winglet result flow characteristics, they are:

1. Lift and drag increase with the increment of angle of attack.

2. Wing with blended winglet results higher $L / D$ ratio than plain wing.

3. Chord lines winglet in $x / c 0.4$ result higher $L / D$ ratio than other chord lines length.

4. CFD can be used to display pressure contour and vorticity on flow.

\section{REFERENCES}

[1] Anderson, J. D., Jr. (2007). Fundamentals of Aerodynamics, 5rd edition. Mc Graw Hill, Inc.,

[2] Dinesh M.; Kenny Mark V.; Dharni Vasudhevan Venkatesan; Santhosh Kumar B.; Sree Radesh R.; V. R. Sanal Kumar (2014), Diagnostic Investigation of Aircraft Performance at Different Winglet Cant Angles, World Academy of Science, Engineering and Technology International Journal of Mechanical, Aerospace, Industrial, Mechatronic and Manufacturing Engineering Vol:8, No:12, 2014

[3] Jacobs, Eastman N., Abbott, Ira H. (1935), Airfoil Section Data Obtained In The NACA Variable-Density Tunnel As Affected by Support Interference And Other Correction, National Advisory Committee For Aeronautics, Report 669 
[4] Myilsamy, D; Yokesh Thirumalai, Premkumar P.S (2015), Performance Investigation of an AircraftWing at Various Cant Angle of Winglet Using CFD Simulation, Altair Technology Conference India

[5] Mulvany, Nicholas J., Li Chen, Jiyuan Y. Tu and Brendon Anderson (2004), Steady State Evaluation of Two Equation RANS Turbulence Models for High Reynolds Number Hydrodynamic Flow Simulations, Final Report, Defence Science and Technology Organisation, Departement of Defence, Australian Goverment

[6] Whitcomb, Richard T. (1976), A Design and Selected Wind Tunnel Results at High Subsonic Speeds for Wingtip Mounted Wingled, NASA Technical Note, July 1976

[7] Bennett David, 2001, The Winggrid: A new Approach to Reducing Induced Drag, Massachusetts Institute of Technology Cambridge, Massachussetts.

[8] Clancy,L.J., 1975, Aerodynamics, Pitman Publishing Limited, London.

[9] La Roche, U. and Palffy, S., 1996, "Wing-Grid, a Novel Device for Reduction of Induced Drag on Wings",Fluid Mechanics Laboratory HTL Brugg-Windisch Ch-5200 Switzerland. 